\title{
Burden of Chronic Kidney Disease by KDIGO Categories of Glomerular Filtration Rate and Albuminuria: A Systematic Review
}

\author{
Molly Murton · Danielle Goff-Leggett · Anna Bobrowska • \\ Juan Jose Garcia Sanchez - Glen James · Eric Wittbrodt • \\ Stephen Nolan · Elisabeth Sörstadius · Roberto Pecoits-Filho • \\ Katherine Tuttle
}

Received: October 13, 2020 / Accepted: November 10, 2020 / Published online: November 24, 2020

(c) The Author(s) 2020

\section{ABSTRACT}

Introduction: The Kidney Disease: Improving Global Outcomes (KDIGO) 2012 guidelines recommend classifying patients by glomerular

Electronic supplementary material The online version of this article (https://doi.org/10.1007/s12325020-01568-8) contains supplementary material, which is available to authorized users.

M. Murton · D. Goff-Leggett · A. Bobrowska Costello Medical Consulting Ltd, Cambridge, Cambridgeshire, UK

J. J. Garcia Sanchez $(\bowtie)$ · G. James · S. Nolan AstraZeneca, Cambridge, Cambridgeshire, UK e-mail: juanjose.garciasanchez@astrazeneca.com

E. Wittbrodt

AstraZeneca, Washington DC, USA

E. Sörstadius

AstraZeneca, Mölndal, Gothenburg, Sweden

R. Pecoits-Filho

Arbor Research Collaborative for Health, Ann Arbor, MI, USA

R. Pecoits-Filho

School of Medicine, Pontifical Catholic University of Paraná, Curitiba, Paraná, Brazil

K. Tuttle

Providence Health Care, Spokane, WA, USA

K. Tuttle

Division of Nephrology, Kidney Research Institute and Institute of Translational Health Sciences,

University of Washington, Seattle, WA, USA filtration rate (GFR) and albuminuria to predict chronic kidney disease (CKD) prognosis. The aim of this systematic review was to explore the epidemiological burden of CKD stratified by the KDIGO 2012 categories.

Methods: MEDLINE ${ }^{\circledR}$ and Embase were searched for observational studies of patients with CKD with results stratified according to the KDIGO 2012 classification. Investigated outcomes were prevalence, incidence, and risk factors and complications of $\mathrm{CKD}$, including mortality.

Results: The review included ten observational studies with 3033 to 46,949 participants, conducted in the USA, China, France, Italy and Spain. The most frequently reported outcome was the prevalence of CKD (GFR categories G3-5), ranging from $2 \%$ to $17 \%$. Most participants were normoalbuminuric, with $0.4-3.2 \%$ macroalbuminuric, and most fell within the KDIGO 2012 low-risk or moderate-risk groups, with $0.9-5.6 \%$ in the high-risk and $0.3-4.8 \%$ in the very high-risk groups. Although scarce, data on the prevalence of comorbidities in CKD according to the KDIGO classification suggest that they increase with albuminuria severity.

Conclusions: Patients with CKD frequently have complications, but only a small proportion have severely increased albuminuria or fall within the KDIGO high-risk or very high-risk groups. These groups, however, are associated with the highest burden of disease, as comorbidities are more prevalent with increasing 
albuminuria severity. New studies framed by the KDIGO 2012 classification are needed to address key gaps in the understanding of CKD burden and outcomes.

Keywords: Albuminuria; Cardiovascular diseases; Chronic kidney disease; CKD; Diabetes mellitus; Hypertension; KDIGO; Prevalence; Renal insufficiency

\section{Key Summary Points}

Why carry out this study?

In 2012, the Kidney Disease: Improving Global Outcomes (KDIGO) organisation issued a set of guidelines recommending that chronic kidney disease (CKD) be classified by both the level of glomerular filtration rate (GFR) and albuminuria.

We conducted a systematic review to explore the uptake of the guidelines (i.e. how many studies use this classification system) and the epidemiology of CKD according to these guidelines (i.e. the prevalence of patients within the GFR/ albuminuria-defined risk groups).

\section{What was learnt from the study?}

A substantial proportion of the general population have $\mathrm{CKD}$, but only a small fraction of patients have severely increased albuminuria or fall within the high-risk or very high-risk groups defined by the KDIGO 2012 guidelines.

These groups, however, have a high prevalence of diabetes, cardiovascular disease and hypertension, especially among those with higher levels of albuminuria.

Testing for albuminuria is therefore valuable for CKD prognosis and management.

\section{DIGITAL FEATURES}

This article is published with digital features, including a summary slide, to facilitate understanding of the article. To view digital features for this article go to https://doi.org/10.6084/ m9.figshare.13207706.

\section{INTRODUCTION}

Chronic kidney disease (CKD) is a substantial public health burden associated with high morbidity and mortality. It is estimated that over 850 million people are affected by kidney diseases worldwide, the majority of whom suffer from CKD [1]. The estimated global prevalence of CKD is $8-16 \%$ [2-4], with the highest rates reported in Saudi Arabia and Belgium (both $24 \%)$, Poland (18\%), Germany (17\%), and the UK and Singapore (both 16\%) [5]. Internationally, CKD was responsible for 1.2 million deaths and 35 million disability-adjusted life-years (DALYs) in 2016 [6]. Global CKD incidence, prevalence, mortality and DALYs have all increased dramatically since 1990 , driven by population growth and aging, and increased numbers of people with diabetes and hypertension [6], which, along with glomerulonephritis, are the leading causes of CKD [3, 6-8].

Kidney function is typically measured via glomerular filtration rate (GFR), with CKD diagnosed when levels are below $60 \mathrm{~mL} / \mathrm{min} /$ $1.73 \mathrm{~m}^{2}$ for 3 months or more [3, 9]. GFR is also used to distinguish between different levels of kidney function, ranging from normal function to kidney failure. Common non-kidney complications of CKD also include myocardial infarction, stroke, heart failure and infections [10]. The treatment of CKD and comorbid conditions imposes a substantial economic burden $[2,11]$. By itself, however, GFR may not optimally predict prognosis [9]. One of the most important predictors of the risk of CKD progression to kidney failure, dialysis, adverse events including cardiovascular risk and premature mortality is elevated albuminuria [12-14]. This has been suggested to have a higher specificity for detecting patients with 
grade $3 / 4$ CKD who are most likely to progress and a greater ability of avoiding those who are less likely to progress [13]. Similarly, patients without impaired eGFR but with elevated albuminuria may also be at higher risk of adverse kidney and cardiovascular outcomes [14]. As such, the consideration of albuminuria would have substantial benefits for the early identification of such patients, proactive management of their disease and healthcare resource planning. The Kidney Disease: Improving Global Outcomes (KDIGO) 2012 guidelines recommend classifying individuals according to six GFR categories and three albuminuria categories [9] (Fig. 1). Through the combined assessment of GFR and albuminuria status, a patient can be more accurately evaluated as being at low, moderately increased, high or very high risk of worsening kidney function and other complications, facilitating improved decision-making in patient monitoring and management $[9,15,16]$.
The epidemiology of CKD has been the subject of previous systematic reviews and metaanalyses [17-19], but in these studies, patients were only classified according to GFR status, making it difficult to quantify the true prevalence of a population at high or very high risk of progression to kidney failure or premature mortality. The epidemiology of CKD according to the 2012 KDIGO categories, as well as the volume of evidence on this topic, is unclear. Therefore, we conducted a systematic review to explore the uptake of the KDIGO 2012 classification system within epidemiologic studies, the relative size and clinical profile of each cohort, and a picture of CKD epidemiology according to the KDIGO 2012 classification system, based on a sample of key countries that were expected to utilise the KDIGO guidelines.

\section{Albuminuria (ACR) categories $(\mathrm{mg} / \mathrm{g}$ )}

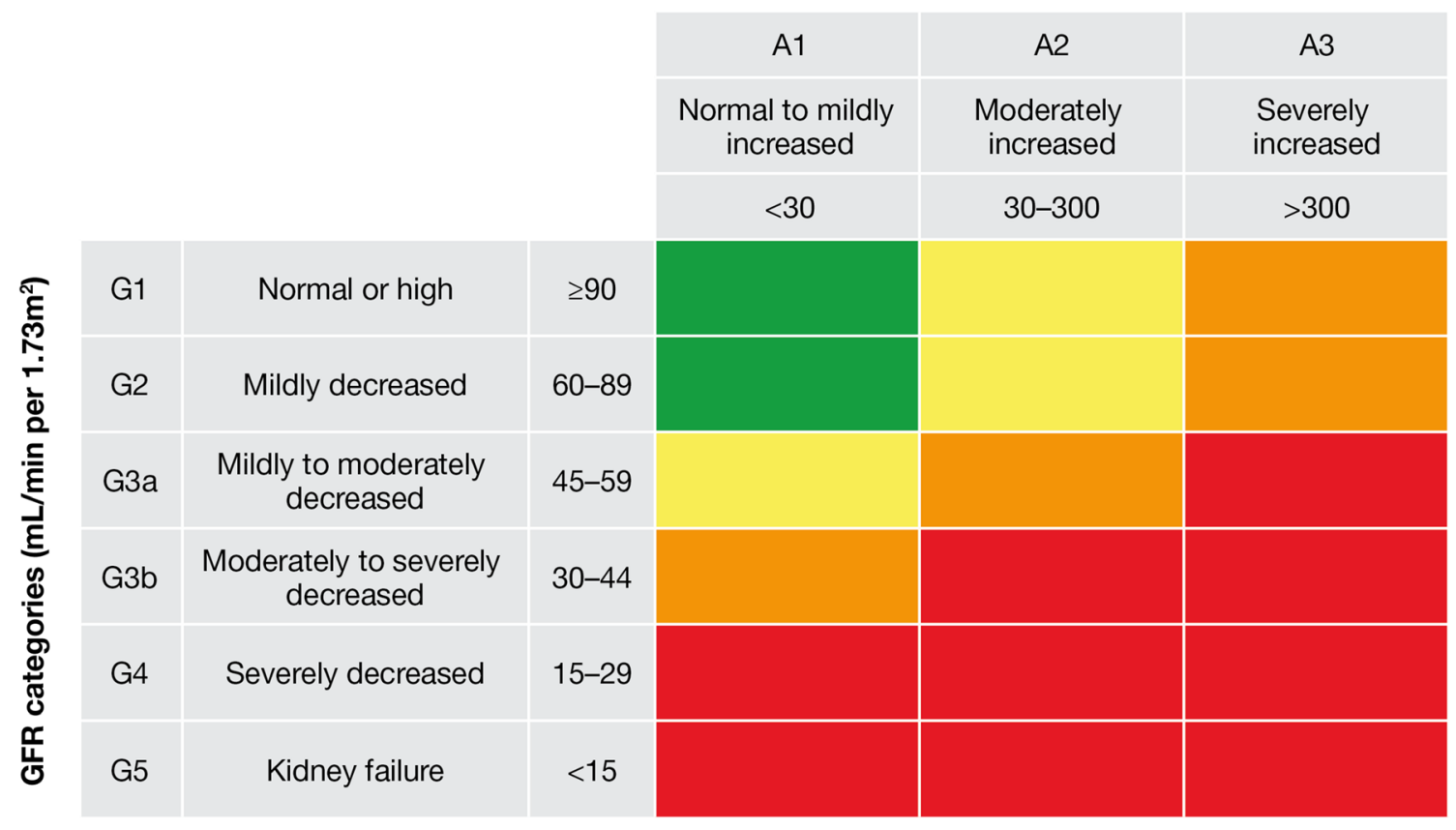

Fig. 1 Prognosis of CKD by GFR and albuminuria categories. Green, low risk of disease progression; yellow, moderately increased risk of disease progression; orange, high risk of disease progression; red, very high risk of disease progression. CKD chronic kidney disease, GFR glomerular filtration rate, $\mathrm{ACR}$ albumin-to-creatinine ratio 


\section{METHODS}

This systematic review was based on a prespecified protocol and conducted in accordance with the standards prescribed by the Centre for Reviews and Dissemination [20] and the Cochrane Collaboration [21]. MEDLINE® and Embase were searched simultaneously via the Ovid SP platform on 10 June 2019. The search terms used are provided in Table $S 1$ in the electronic supplementary material. The bibliographies of relevant published systematic reviews were hand-searched to find additional articles that were not identified in the electronic database searches. Grey literature searches included conference proceedings of six major nephrology, cardiology and diabetes congresses held between 2017 and 2019, and three major CKD-related registries (Table S2). Expert advice was sought to identify potentially relevant articles that were not captured by the electronic database searches or supplementary searches.

Two independent reviewers (MM, DGL) screened the title and abstract of each record (stage 1), as well as the full texts of all potentially eligible records identified in stage 1 (stage 2). A third independent reviewer (AB) resolved any disagreements. Detailed eligibility criteria are given in Table 1 . Eligible publications included English language articles reporting on relevant non-interventional studies involving adult patients with $\mathrm{CKD}$, in which relevant outcomes were stratified according to the KDIGO 2012 guidelines or similar classification, with data stratified by albuminuria and GFR status or albuminuria status alone. Studies that stratified data by GFR status alone were excluded. Relevant articles were limited to those published in 2012 or later (i.e. since the publication of the KDIGO 2012 guidelines) and conducted in the USA, China or a European Union Five (EU5) country (France, Germany, Italy, Spain or the UK).

Relevant outcomes were the prevalence of $\mathrm{CKD}$, the prevalence of CKD risk factors and complications (e.g. diabetes, hypertension, heart failure and cardiovascular disease [CVD]), and the incidence of CKD, CVD complications (e.g. myocardial infarction and stroke), hospitalisations for heart failure, and CVD-related or all-cause mortality. Data were extracted and summarised qualitatively, as ranges of prevalence; owing to the nature of this review a meta-analysis was not performed and any numbers have been given as reported in the included studies or arrived at by calculating a simple proportion (ratio of participants with a specific characteristic to the total population).

A single reviewer (MM or DGL) extracted data from the included studies into a prespecified extraction grid and assessed study quality using the Joanna Briggs Institute (JBI) Critical Appraisal Checklist for Prevalence Studies 2017 [22]. Extracted data and quality assessments were independently verified by a second reviewer (MM or DGL), with discrepancies arbitrated by a third reviewer $(\mathrm{AB})$.

\section{Compliance with Ethics Guidelines}

This article is based on previously conducted studies and does not contain any new studies with human participants or animals performed by any of the authors.

\section{RESULTS}

\section{Study Selection}

Electronic database searches yielded 4286 records. After title/abstract screening, 249 potentially relevant records were selected for full text review, of which 11 were included. A complete list of articles excluded at the full text review stage is provided in Table S3. Supplementary searches yielded 3262 records, of which two met the inclusion criteria. One article was screened on the basis of expert advice and met the inclusion criteria [23]. A total of 14 publications reporting on 10 unique non-interventional studies were included in the review (Fig. 2, Table S4). The number of articles that were excluded because of not reporting CKD epidemiology outcomes according to KDIGO classification was 1334 (Fig. 2). From this, it can be calculated that only $1.04 \%$ of articles reported such outcomes using the KDIGO 
Table 1 SR eligibility criteria

\begin{tabular}{|c|c|c|}
\hline Category & Inclusion criteria & Exclusion criteria \\
\hline Population & $\begin{array}{l}\text { Adult patients with CKD stages 2, 3a, 3b, } 4 \text {, } \\
\text { 5/ESRD, categorised according to the } \\
\text { KDIGO } 2012 \text { classification or similar } \\
\text { Mixed populations, if the outcomes are } \\
\text { reported separately for the population of } \\
\text { interest }\end{array}$ & $\begin{array}{l}\text { Population does not include patients with } \\
\text { CKD of a relevant stage or classification, or } \\
\text { does not report results separately for this } \\
\text { subgroup } \\
\text { Animal/in vitro studies }\end{array}$ \\
\hline Intervention/comparator & Any or none & $\mathrm{N} / \mathrm{A}$ \\
\hline Outcomes & $\begin{array}{l}\text { Country or regional-level prevalence, incidence } \\
\text { or mortality reported for the following } \\
\text { health states, including but not limited to: } \\
\text { CKD albuminuria categories, with } \\
\text { albuminuria measured by methods including } \\
\text { but not limited to: } \\
\text { UACR } \\
\text { PCR } \\
\text { AER } \\
\text { PER } \\
\text { Protein reagent strip } \\
\text { Level of overlap between CKD, T2DM and } \\
\text { heart failure } \\
\text { Cardiovascular complications (e.g. MI, stroke, } \\
\text { angina, MACE, hospitalisation for heart } \\
\text { failure) } \\
\text { Hypertension }\end{array}$ & No relevant epidemiological outcomes \\
\hline Study type & $\begin{array}{l}\text { Non-interventional studies, e.g. observational } \\
\text { studies or population surveys of any design, } \\
\text { including cohort studies, cross-sectional } \\
\text { surveys, case-control studies, registry studies, } \\
\text { chart reviews etc. } \\
\text { Meta-analyses of relevant study designs }\end{array}$ & $\begin{array}{l}\text { Any other study type, e.g. RCTs, case reports/ } \\
\text { series }\end{array}$ \\
\hline Publication type & $\begin{array}{l}\text { Original research studies } \\
\text { Conference abstracts } \\
\text { SRs of relevant primary publications (these } \\
\text { were considered relevant at the title/abstract } \\
\text { review stage and hand-searched for relevant } \\
\text { primary studies, but excluded during the full- } \\
\text { text review stage) }\end{array}$ & $\begin{array}{l}\text { Irrelevant publication types including narrative } \\
\text { reviews, commentaries, editorials }\end{array}$ \\
\hline
\end{tabular}


Table 1 continued

\begin{tabular}{lll}
\hline Category & Inclusion criteria & Exclusion criteria \\
\hline Other criteria & Studies conducted in the USA, China or EU5 & Studies conducted in any other geographical \\
& country (France, Germany, Italy, Spain, UK) & location \\
& Studies published in or after 2012 & Studies published before 2012 \\
& Conference abstracts published in or after & Conference abstracts published before 2017 \\
2017 & Full text in any other language \\
& Full text in English & \\
\hline
\end{tabular}

$A E R$ albumin excretion rate, $C K D$ chronic kidney disease, ESRD end-stage renal disease, EUS European Union Five, $K D I G O$ Kidney Disease: Improving Global Outcomes, $M A C E$ major adverse cardiac events, $M I$ myocardial infarction, $N / A$ not applicable, $P C R$ protein-to-creatinine ratio, $P E R$ protein excretion rate, $R C T$ randomised controlled trial, $S R$ systematic review, T2DM type 2 diabetes mellitus, UACR urinary albumin-to-creatinine ratio

${ }^{\dagger}$ Heart failure was defined on the basis of the New York Heart Association classification [46]

classification $(14 / 1348 \times 100)$. Any results presented below have been reported in the included studies or calculated through a simple proportion; no quantitative synthesis has been conducted.

\section{Study Characteristics}

Table 2 summarises the characteristics of the 10 studies included in this systematic review. Five studies were conducted in the USA [24-28], one in China [29], one in the USA and China [30], one in Italy [31], one in Spain [32] and one in France [23]. Of the six studies that reported study location(s), all involved participants from multiple geographical locations, with the exception of one that was based in a single province in eastern Sardinia [31]. The earliest data collection period was 1988-1994 [26], while the most recent data were collected in 2013-2016 [23, 27]. Sample size ranged from 3033 [23] to 46,949 participants [30]. All studies involved data from cross-sectional surveys and registry analyses $(6 / 10)$ or cohort studies (4/10).

In all studies, CKD was classified according to clinical test results rather than administrative codes (Table 2). Estimated GFR (eGFR) was calculated using the CKD Epidemiology Collaboration (CKD-EPI) equation in eight studies, the Modification of Diet in Renal Disease (MDRD) equation in one study [29], and both in another study [31]. Eight studies used urinary albuminto-creatinine ratio (UACR) to determine albuminuria status, one used urinary protein and albumin concentrations only [31], and another used several methods, including UACR, proteinto-creatinine ratio (PCR), albumin excretion rate (AER) and protein excretion rate (PER) [23].

In seven studies, patients were recruited from the general population, whereas in three studies, patients were from specific groups or settings. Of the latter, one evaluated hypertensive patients from a Spanish primary care setting [32], another analysed a subset of patients from a larger sample of the general population who were prescribed antihypertensive medication [28], and a third involved nephrologist-referred outpatients from the French Chronic Kidney Disease-Renal Epidemiology and Information Network (CKD-REIN), a cohort study investigating the determinants of prognosis and care in patients with CKD [23].

\section{Patient Demographics, Aetiology and Baseline Comorbidities}

Patient demographics are summarised in Table 3. Average age was reported in eight studies and ranged between 42.6 years [30] and 67.5 years [28]. Gender ratio was reported in five studies and ranged from $42.3 \%$ [31] to $65 \%$ male [23]. Racial demographics were reported in 

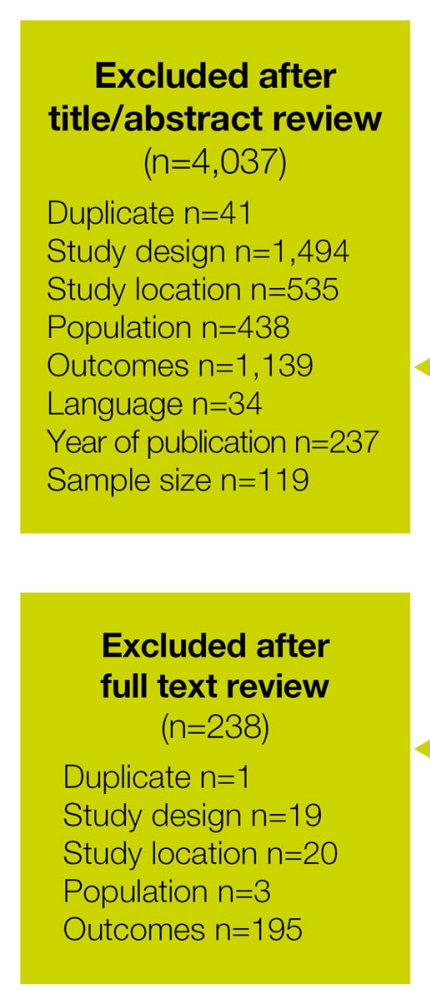

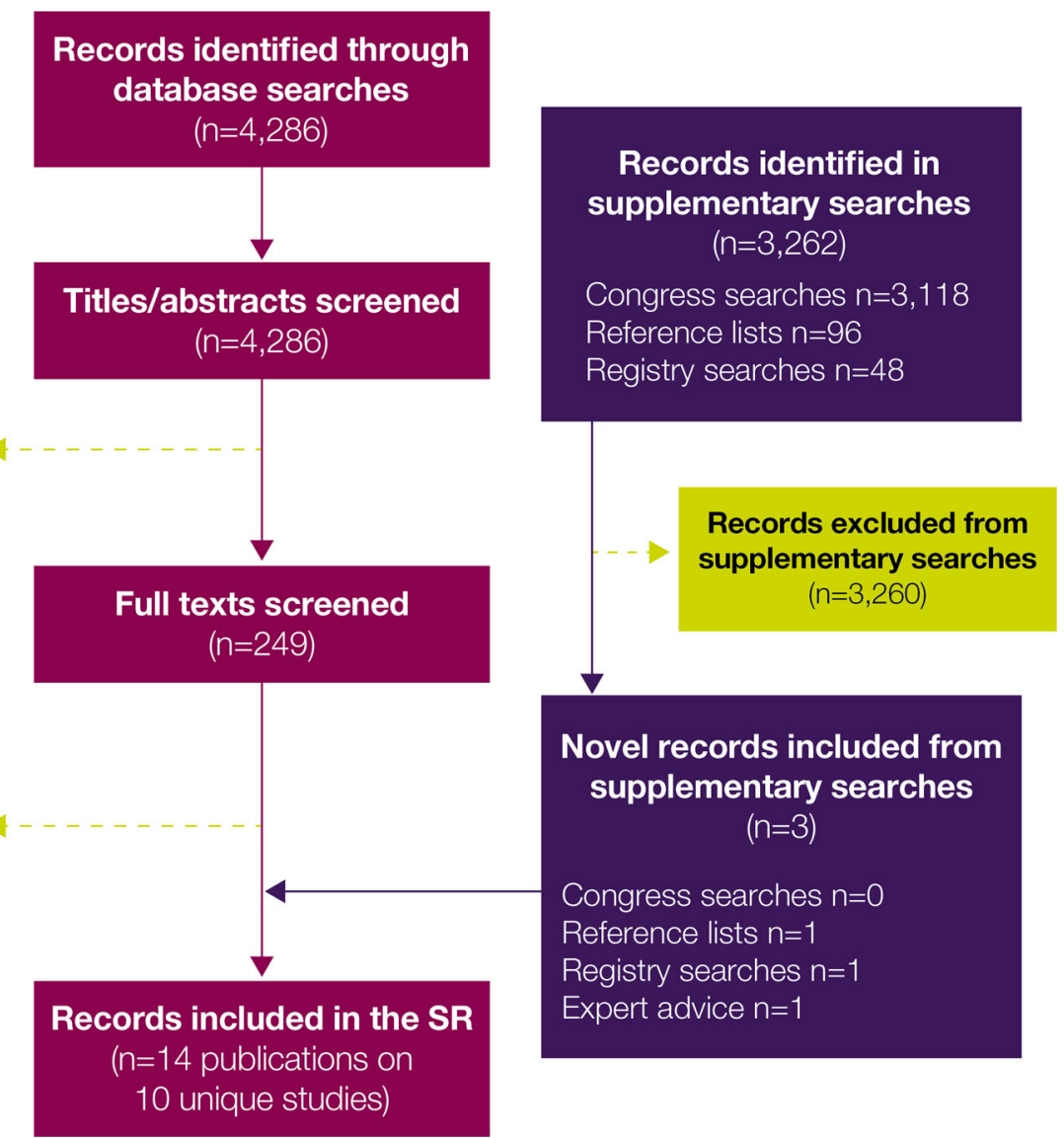

Fig. 2 PRISMA flowchart of records included and excluded in the review. Expert advice: one article was identified on the basis of advice from KT and RPF.

four studies; black individuals comprised between $10.6 \% \quad[30]$ and $50.1 \%$ [28] of participants.

Baseline comorbidity data are presented in Table 4. Of the seven studies that involved general population samples, four provided information on the prevalence of hypertension and diabetes at baseline, which ranged from $24.5 \%$ [26] to $47.4 \%$ [24] and 5\% [30] to $16.6 \%$ [24] respectively.

\section{Stratified Prevalence of CKD}

\section{General Population Cohorts}

The most frequently reported outcome was the point prevalence of CKD in the general population, reported in seven studies across the USA, China and Italy [24, 29-31] (Fig. 3). The overall
PRISMA preferred reporting items for systematic reviews and meta-analyses, SR systematic review

prevalence of patients with GFR categories G3-5, the clinical definition of CKD, was $2-17 \%$. Prevalence appeared lower in China $(2-3 \%)$ and Italy (3\%) than in the USA (6-17\%).

In individual studies, across GFR categories G2-5, the prevalence of individuals with normal albuminuria (UACR $<30 \mathrm{mg} / \mathrm{g}$ ) was 27.4-56.4\%, moderately increased albuminuria (UACR $30-300 \mathrm{mg} / \mathrm{g}$ ) was $2.9-10.0 \%$, and severely increased albuminuria (UACR $>300 \mathrm{mg} / \mathrm{g}$ ) was $0.4-3.2 \%$. The ranges of prevalence in GFR category G1 were $35.5-59.8 \%, 1.9-6.5 \%$ and $0.2-1.8 \%$ in normal albuminuria, moderately increased albuminuria and severely increased albuminuria, respectively. On the basis of the combination of GFR status (across categories G2-5) and albuminuria status (across categories A1-3), 24.8-51.4\% of 


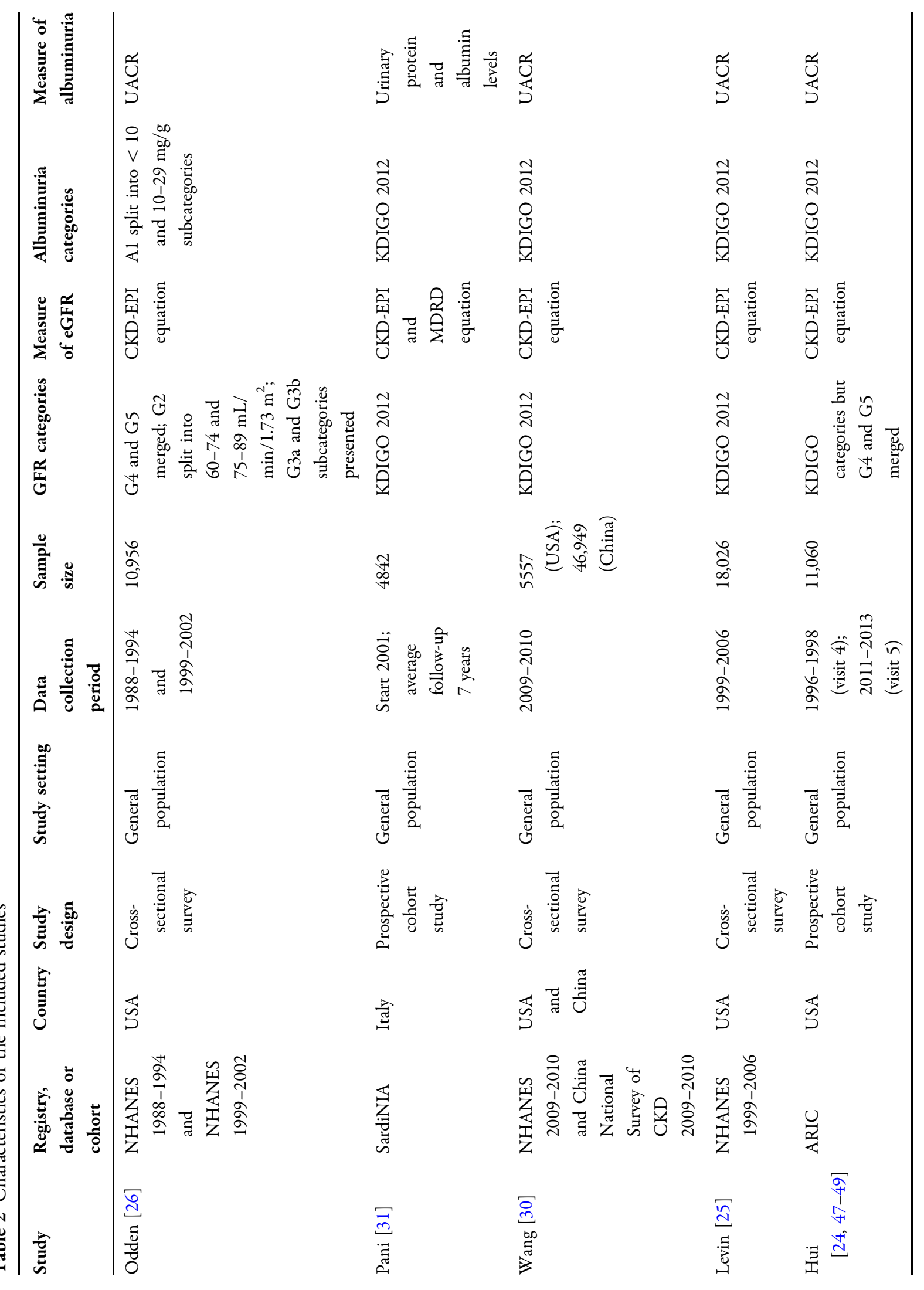




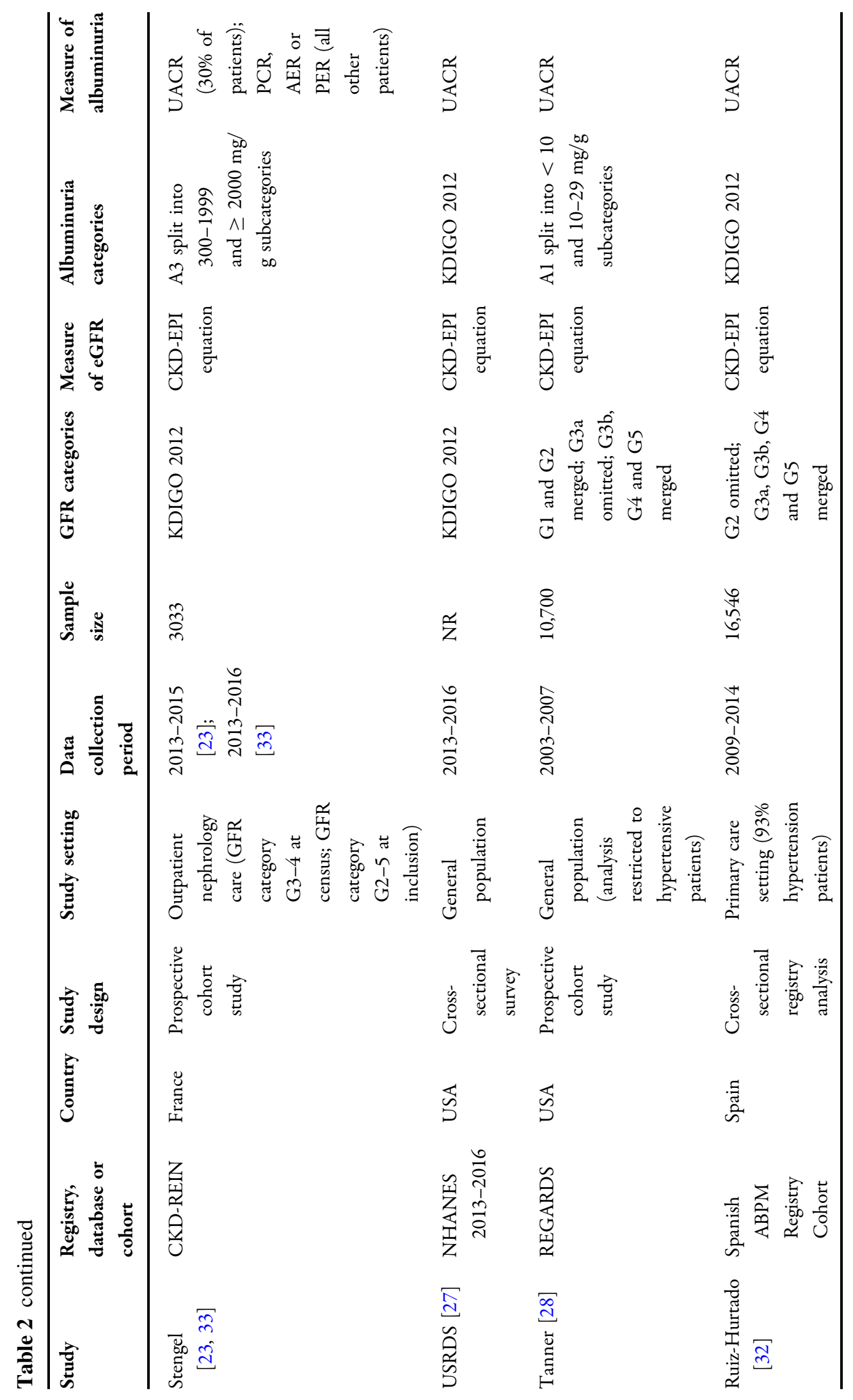




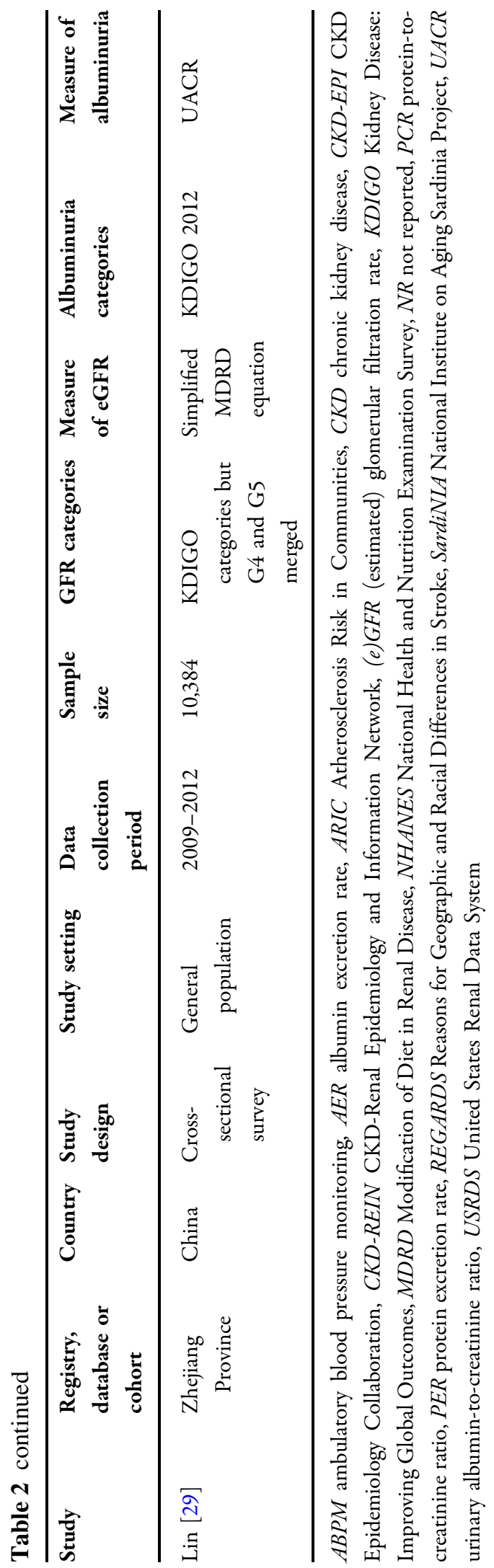

participants fell within the KDIGO 2012 lowrisk group, $3.7-13.4 \%$ within the moderately increased risk group, $0.9-5.6 \%$ within the highrisk group and $0.3-4.8 \%$ within the very highrisk group. For the very high-risk group, prevalence was lower in China (0.3-0.4\%) and Italy $(0.4 \%)$ than in the USA (1.1-4.8\%).

\section{Selected Cohorts}

Two studies documented the prevalence of patients per the KDIGO 2012 albuminuria categories in specific cohorts selected for CKD or hypertension. In one cohort in a French nephrology outpatient setting, eligible patients had $e G F R<60 \mathrm{~mL} / \mathrm{min} / 1.73 \mathrm{~m}^{2}$ for at least 1 month, with no prior chronic dialysis or transplantation [23] (Fig. 4). Normal albuminuria (UACR $<30 \mathrm{mg} / \mathrm{g}$ ) was observed in $23.6 \%$ of these patients, moderately increased albuminuria (UACR $30-299 \mathrm{mg} / \mathrm{g}$ ) in $27.4 \%$, severely increased albuminuria (UACR 300-1999 mg/g) in 29.0\% and high-grade albuminuria (UACR $\geq 2000 \mathrm{mg} / \mathrm{g}$ ) in $7.1 \%$. The other cohort consisted primarily of individuals with hypertension (93\%) in a Spanish primary care setting [32]. Among those with eGFR $<60 \mathrm{~mL} / \mathrm{min} / 1.73 \mathrm{~m}^{2}, 74.4 \%$ had normal albuminuria (UACR $<30 \mathrm{mg} / \mathrm{g}$ ), 20.1\% had moderately increased albuminuria (UACR $30-300 \mathrm{mg} / \mathrm{g}$ ) and $5.5 \%$ had severely increased albuminuria (UACR $\geq 300 \mathrm{mg} / \mathrm{g}$ ). There were no available data on high rates of eGFR (G1 equivalent) in the selected cohorts. This was as expected as such cohorts frequently include patients with more advanced stages of disease.

\section{Prevalence of CKD Risk Factors and Complications}

In the Spanish hypertensive cohort, the prevalence of diabetes was higher in patients with CKD that had greater albuminuria severity; among patients with eGFR $<60 \mathrm{~mL} / \mathrm{min} /$ $1.73 \mathrm{~m}^{2}$, diabetes was present in $26 \%, 43 \%$ and $53 \%$ of individuals with normal albuminuria, moderately increased albuminuria and severely increased albuminuria, respectively (Fig S1) [32]. In the French CKD cohort, the proportion of patients with atherosclerotic CVD was higher 


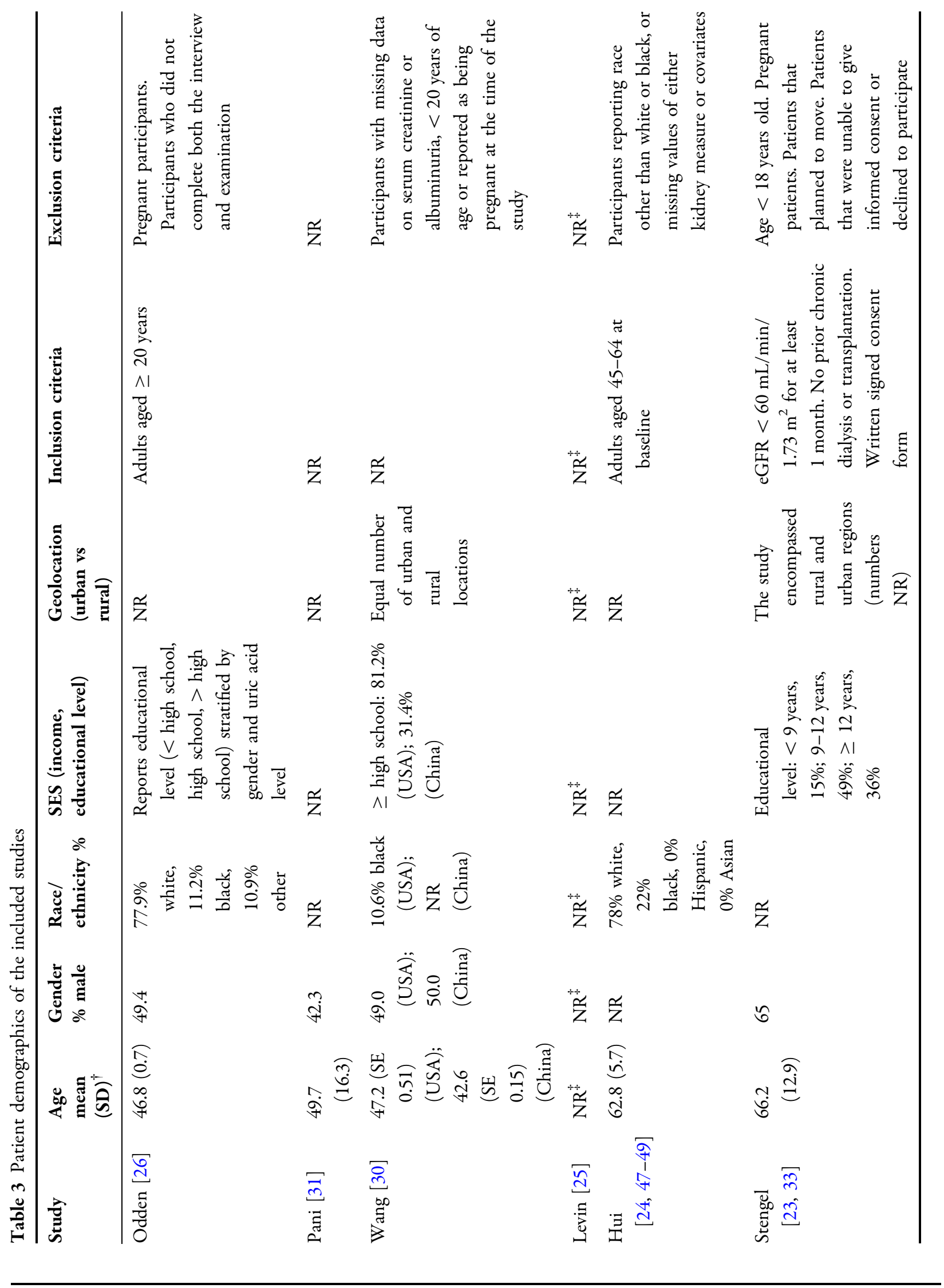




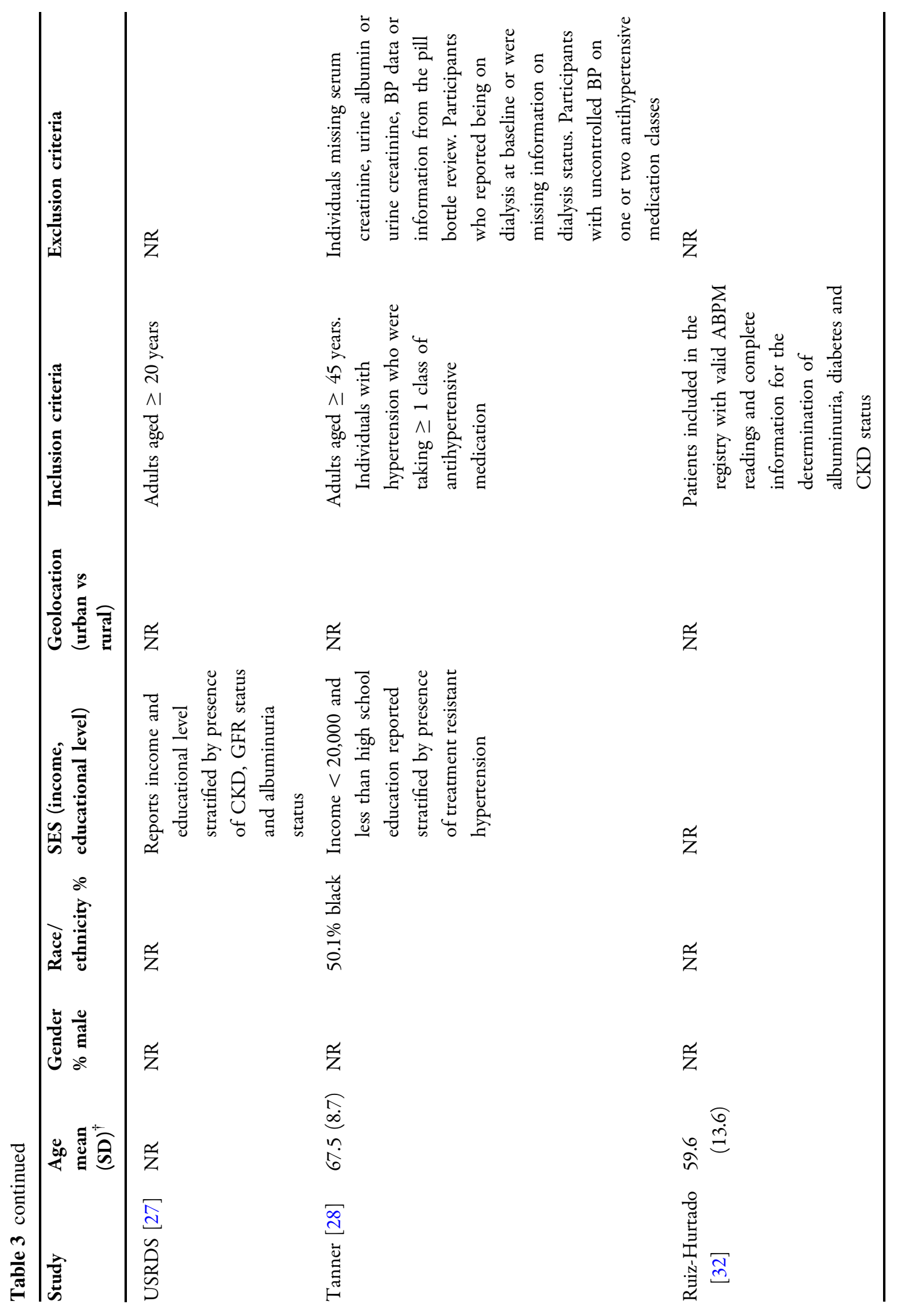




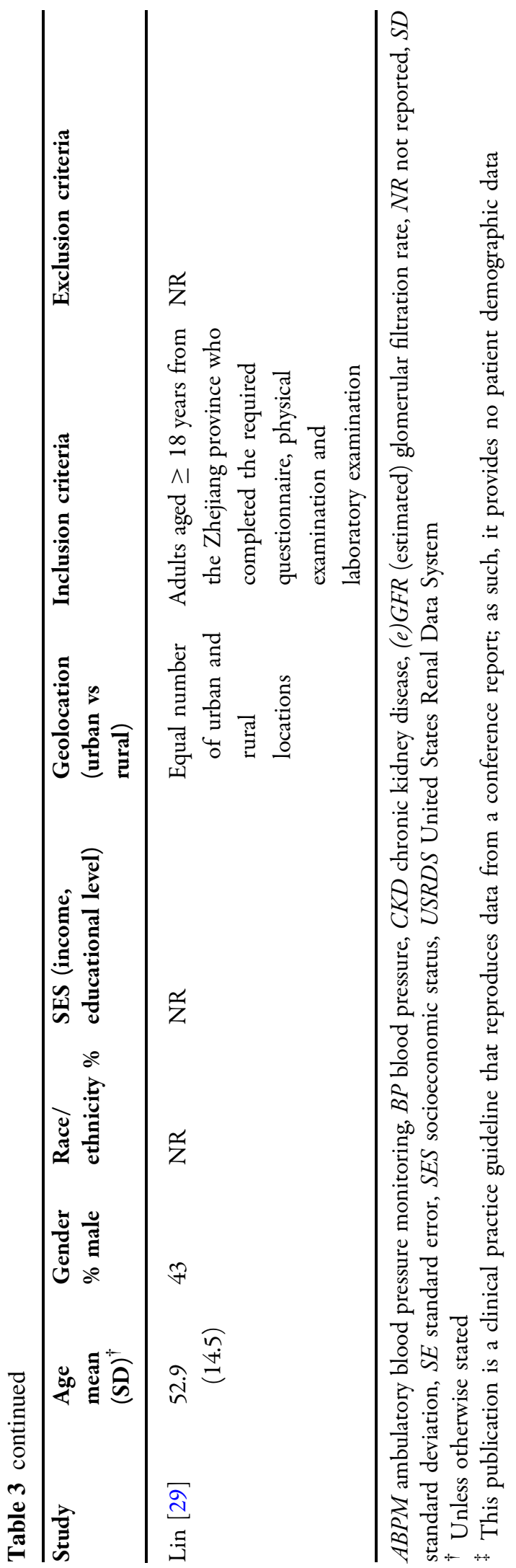

in moderately albuminuric (30.9\%) and severely albuminuric (34.4\%) than in patients with normal albuminuria (28.5\%) [33]. In an analysis of USA-based hypertensive patients, the prevalence of apparent treatment-resistant hypertension was found to increase with both worsening GFR status and increasing albuminuria severity [28]. In hypertensive patients with eGFR $45-59 \mathrm{~mL} / \mathrm{min} / 1.73 \mathrm{~m}^{2}$, the prevalence of apparent treatment-resistant hypertension was $17.2 \%, 26.9 \%, 32.2 \%$ and $50.7 \%$ in groups with $\mathrm{UACR}<10, \quad 10-29, \quad 30-299$ and $\geq 300 \mathrm{mg} / \mathrm{g}$, respectively. In those with eGFR $<45 \mathrm{~mL} / \mathrm{min} /$ $1.73 \mathrm{~m}^{2}$, the corresponding figures were $22.5 \%$, $24.5 \%, 32.8 \%$ and $56.4 \%$.

Other relevant outcomes such as the prevalence or incidence of CKD complications, heart failure, myocardial infarction, stroke, or CVD and all-cause mortality according to the KDIGO classification were not identified.

\section{Study Quality}

There was sufficient information to assess the quality of four of the ten studies, all of which were judged to be of high quality, whereas the overall quality of the remaining six studies was unclear (see supplementary data and Table S5).

\section{DISCUSSION}

This systematic review of the epidemiological burden of CKD uniquely considered both GFR and albuminuria status, consistent with the KDIGO 2012 classification system and recommendations of the recent KDIGO Consensus Conference $[9,34]$. This provides a very valuable different perspective from previous work that has only classified CKD epidemiology according to GFR status and, particularly, allows delineation of the groups that are likely to be at highest risk of adverse outcomes and progression to kidney failure. Measurement of albuminuria should be a key component of risk assessment for CKD [9], in that higher levels of albuminuria are associated with a faster rate of GFR decline and higher risk of kidney failure and mortality $[13,14,35]$. 
Table 4 Baseline comorbidity data

\begin{tabular}{|c|c|c|c|c|c|c|c|c|}
\hline Study & $\begin{array}{l}\text { Hypertension } \\
\%\end{array}$ & $\begin{array}{l}\text { Diabetes }^{\dagger} \\
\%\end{array}$ & $\begin{array}{l}\text { SBP } \\
(\mathrm{mmHg}) \\
\text { mean }(\mathrm{SD})\end{array}$ & $\begin{array}{l}\text { BMI }(\mathbf{k g} / \\
\left.\mathbf{m}^{2}\right) \text { mean } \\
(\mathrm{SD})^{\ddagger}\end{array}$ & $\begin{array}{l}\text { History } \\
\text { of CVD/ } \\
\text { CVD } \\
\text { events \% }\end{array}$ & $\begin{array}{l}\text { History } \\
\text { of MI \% }\end{array}$ & $\begin{array}{l}\text { History } \\
\text { of } \\
\text { stroke } \\
\%\end{array}$ & $\begin{array}{l}\text { History } \\
\text { of HF \% }\end{array}$ \\
\hline Odden [26] & 24.5 & 6.2 & $123.9(0.8)$ & $27.8(0.3)$ & NR & 3.4 & 1.9 & 2.3 \\
\hline Pani [31] & 32 & 9.1 & NR & $25.9(4.7)$ & 5.6 & NR & NR & NR \\
\hline Wang [30] & $\begin{array}{l}35.1 \text { (USA); } \\
30.4 \text { (China) }\end{array}$ & $\begin{array}{l}10.7 \\
\text { (USA); } \\
5.0 \\
\text { (China) }\end{array}$ & $\begin{array}{l}120.3 \text { (SE } \\
0.51) \\
\text { (USA); } \\
125.2 \text { (SE } \\
0.18) \\
\text { (China) }\end{array}$ & $\begin{array}{l}28.7 \text { (SE } \\
0.13) \\
\text { (USA); } \\
23.5 \text { (SE } \\
0.03) \\
\text { (China) }\end{array}$ & $\begin{array}{l}5.2 \\
\text { (USA); } \\
2.0 \\
\text { (China) }\end{array}$ & NR & NR & NR \\
\hline Levin [25] & NR & NR & NR & NR & NR & NR & NR & NR \\
\hline $\begin{array}{l}\text { Hui } \\
\qquad[24,47-49]\end{array}$ & 47.4 & 16.6 & $127.6(19)$ & $28.8(5.6)$ & 13.9 & NR & NR & NR \\
\hline $\begin{array}{l}\text { Stengel } \\
\qquad[23,33]\end{array}$ & 91 & 43 & $142(20)$ & $29(6)$ & 53 & NR & NR & NR \\
\hline USRDS [27] & NR & NR & NR & NR & NR & NR & NR & NR \\
\hline Tanner [28] & NR & 34.7 & $132.9(14.1)$ & NR & NR & 19.3 & 10.7 & NR \\
\hline $\begin{array}{l}\text { Ruiz-Hurtado } \\
\text { [32] }\end{array}$ & 93 & 25.3 & NR & $29.3(4.9)$ & 12.4 & NR & NR & NR \\
\hline Lin [29] & NR & NR & $133.4(24.1)$ & $23.1(3.99)$ & NR & NR & NR & NR \\
\hline
\end{tabular}

$B M I$ body mass index, $C V D$ cardiovascular disease, $H F$ heart failure, $M I$ myocardial infarction, $N R$ not reported, $S B P$ systolic blood pressure, $S D$ standard deviation, $S E$ standard error, USA United States of America, USRDS United States Renal Data System

$\dagger$ Diabetes subtype unspecified in all studies

* Unless otherwise stated.

We included 14 relevant publications reporting on 10 non-interventional studies. The modest number of relevant studies (compared with the literature focusing on GFR alone) may reflect the relative recency of the publication of the KDIGO recommendations and the time required to perform and disseminate epidemiological studies. It may also suggest that the evaluation of albuminuria status remains limited. UACR testing is still not widely practised, due to lack of awareness and coordinated initiatives to encourage implementation in healthcare systems [36], and possibly lower practicality of urine- versus blood-based diagnostics. This is despite good evidence of its prognostic value. A 2010 meta-analysis, for example, revealed that the risk of all-cause and CVD-related death both increase as UACR rises, independent of GFR $[37,38]$.

The prevalence of CKD in a general population sample, stratified according to the KDIGO 2012 recommendations, was reported in seven out of ten studies from the USA, China and Italy. The overall prevalence of patients with GFR categories G3-5 ranged from $2 \%$ to $17 \%$, echoing a previous report that the global 

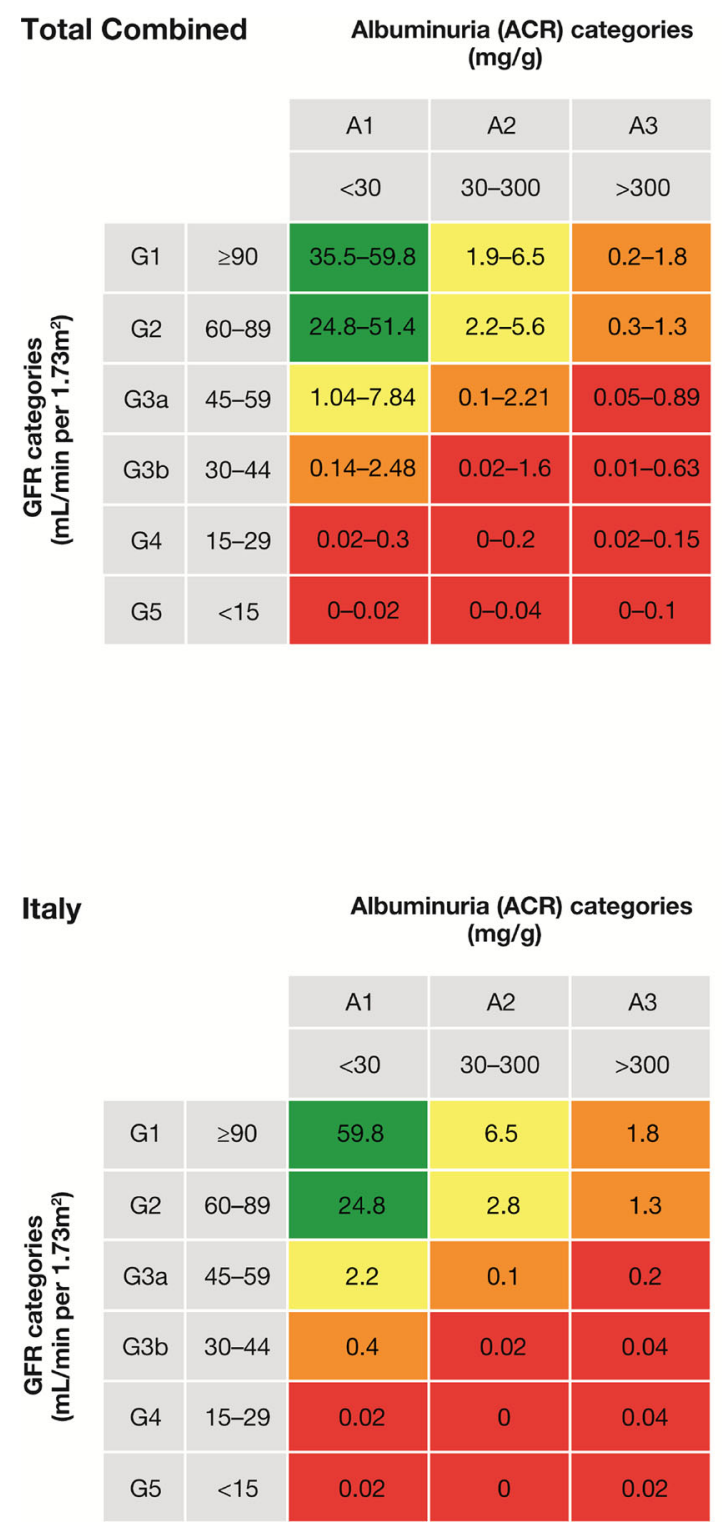

Fig. 3 Prevalence of each KDIGO 2012 category in general population samples. Tables informed by seven studies (total combined), five studies (USA), one study (Italy), two studies (China). Note that the number of studies does not add up to seven as one study reported data for both USA and China. Numbers represent percentage of entire sample. Totals for each row and column are not presented as the highest prevalence in one category may not come from the same study as the highest prevalence in

prevalence of CKD is $8-16 \%$ [3]. Prevalence was considerably higher in the USA than China or Italy, consistent with existing evidence [6].
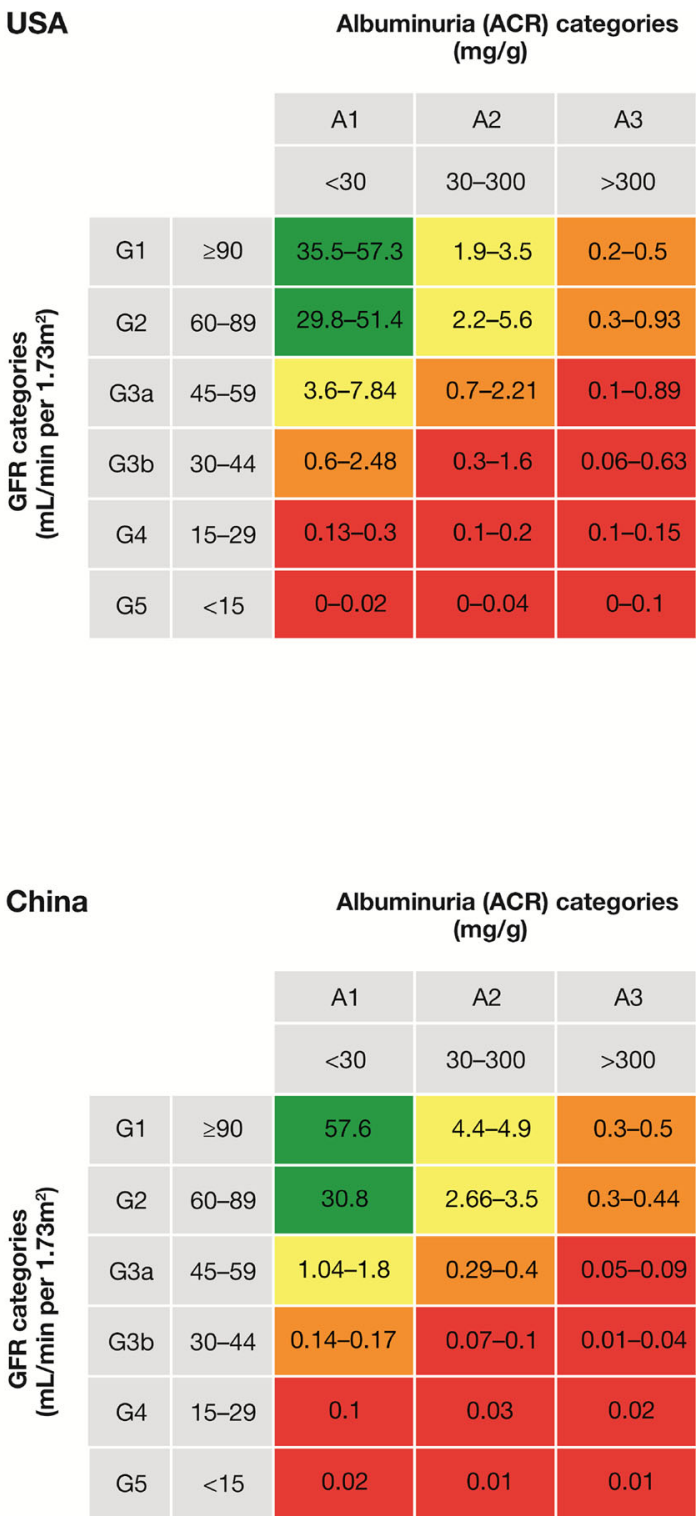

another category, which would misleadingly lead to a summation of values across categories to result in a range where the upper value appears to be $>100 \%$. Green, low risk of disease progression; yellow, moderately increased risk of disease progression; orange, high risk of disease progression; red, very high risk of disease progression. ACR albumin-to-creatinine ratio, GFR glomerular filtration rate, KDIGO Kidney Disease: Improving Global Outcomes

The prevalence of normal albuminuria, moderately increased albuminuria and severely increased albuminuria (across GFR categories G2-5) was 27.4-56.4\%, $2.9-10.0 \%$ and 


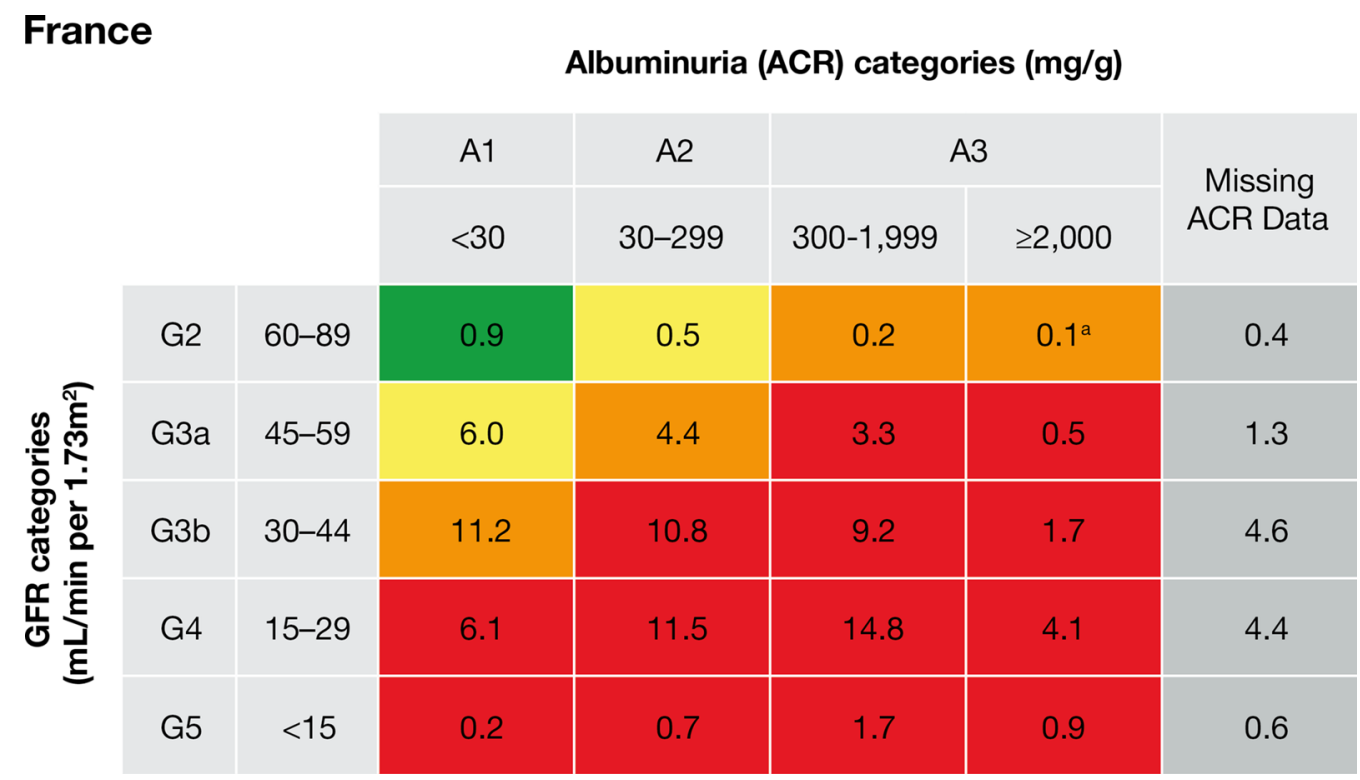

Fig. 4 Prevalence of each KDIGO 2012 category in a cohort of patients with CKD. Data from Stengel 2019 [23]. 'Patients considered to be at high risk of CKD progression by the KDIGO 2012 guidelines, but very high risk by Stengel 2019 [23]. Numbers represent percentage of entire sample. Green, low risk of disease progression;

0.4-3.2\%, respectively. Across GFR categories G2-5 and albuminuria categories A1-3, $3.7-13.4 \%$ of participants fell within the KDIGO 2012 moderate risk CKD, $0.9-5.6 \%$ within the high-risk group and $0.3-4.8 \%$ within the very high-risk group. These numbers are broadly consistent with those of a recent cross-sectional study that evaluated the global prevalence of CKD stratified by the KDIGO 2012 categories based on the results of general population CKD screening programmes performed in China, Mongolia, India, Nepal, Iran, Nigeria, Moldova and Bolivia [39]. Taken together, the data imply that a significant proportion of the general population may experience CKD progression and complications $[9,15,16]$, minimising their quality-of-life and chances of survival, as well as imposing a substantial burden on healthcare resources [2, 11]. Measuring albuminuria also provides an additional insight in that the prevalence of those at high and very high risk of progression is lower than the prevalence if only accounting for GFR status [40]. yellow, moderately increased risk of disease progression; orange, high risk of disease progression; red, very high risk of disease progression; grey, patients without ACR data. ACR albumin-to-creatinine ratio, $\mathrm{CKD}$ chronic kidney disease, GFR glomerular filtration rate, KDIGO Kidney Disease: Improving Global Outcomes

Since this systematic review was conducted, two further articles have been published reporting the prevalence of the KDIGO 2012 albuminuria categories from the UK, Germany, France and USA $[41,42]$ (Table S6). The cohorts included patients with CKD, with a higher proportion of moderately and severely increased albuminuria compared with the general population cohorts included in this systematic review. The numbers mirror those of the one study included in this systematic review that recruited patients with CKD alone [23] (Fig. 4).

Very little information has been published on the prevalence of CKD risk factors and complications in patients stratified by the KDIGO 2012 categories; only three of the included studies reported such outcomes. From the scarce data available, diabetes, apparent treatment-resistant hypertension and atherosclerotic CVD [28, 32, 33] were found to be more prevalent with increasing albuminuria severity. Further epidemiological studies are needed to confirm and expand on these initial 
findings, but they are consistent with evidence that albuminuria heralds CKD progression and complications $[9,15,16,37,38]$. These data highlight the need for the screening of both GFR and albuminuria status in populations at risk for CKD, particularly those with diabetes or hypertension, and for the regular monitoring of individuals with CKD [3, 12, 25, 43].

A notable strength of the included data is that CKD was classified according to clinical tests in every study rather than administrative codes, providing a robust appraisal of kidney function. Study quality was judged to be high in four out of ten included studies (see supplementary data and Table S5). Within the remaining six studies, some risk of bias was recognised as a result of missing methodological information but this was judged as low and unlikely to threaten internal or external data validity.

No evidence regarding the incidence of CKD, CVD complications, or CVD-related or all-cause mortality according to the KDIGO 2012 categories was identified. Moreover, data on the prevalence of CKD risk factors and complications according to albuminuria status were only obtained from studies of specific high-risk groups (i.e. CKD or hypertensive patient cohorts), which represents a major data gap to be addressed by future longitudinal studies to more completely and accurately assess CKD burden and outcomes.

We aimed to provide an overview of the uptake of the KDIGO 2012 guidelines and volume of evidence available on CKD epidemiology according to the GFR and albuminuria categories. As such, a meta-analysis was beyond the scope of this work, and the review is limited to a qualitative summary and description of the results as reported in the individual studies. To aim to provide a multinational overview in a sample of countries likely to have the highest uptake of the KDIGO guidelines, the review focused on studies performed in the USA, China or EU5 countries. As such, the results may not fully represent the international epidemiological burden of CKD, given the strong USA focus of the data and previous evidence that prevalence varies by race/ethnicity $[44,45]$ and geographical location [2,6]. However, as a result of the consistent estimates reported in the studies that were identified, it is expected that these values would be fairly generalisable to other countries.

Along with further observational studies to address the current data gaps in CKD prevalence and overlapping comorbidities according to albuminuria status in general population cohorts, useful future work would include a comprehensive review that expanded the included countries to all countries and languages with published data on the epidemiology of CKD according to the KDIGO 2012 guidelines. Associations between CKD prevalence and country-specific parameters including healthcare spending and economic climate could also be useful to explore within this.

\section{CONCLUSIONS}

This systematic review identified ten studies with outcomes stratified according to GFR and albuminuria status, consistent with the KDIGO 2012 recommendations. These studies reveal that a substantial proportion of the general population have $\mathrm{CKD}$, which has important implications for adverse complications, healthrelated quality-of-life, survival, and healthcare resource planning and utilisation. While CKD is common, a small proportion of patients have severely increased albuminuria or fall within the KDIGO high- or very high-risk groups. These groups, however, have a high presence of diabetes, CVD and hypertension, especially with higher degrees of albuminuria. As such, testing for albuminuria is valuable for CKD prognosis and management. There is also a need for comprehensive longitudinal studies to address key gaps (incidence of CKD, complications, CVD and mortality according to the KDIGO classification) in understanding the burden and outcomes of CKD defined by KDIGO 2012 recommendations. 


\section{ACKNOWLEDGEMENTS}

Funding. This study was sponsored by AstraZeneca plc. The journal Rapid Service and Open Access Fees were funded by AstraZeneca plc.

Editorial Assistance. Editorial assistance in the preparation of this article was provided by Dr David Pritchett of Costello Medical, UK. Support for this assistance was funded by AstraZeneca plc.

Authorship. All named authors meet the International Committee of Medical Journal Editors (ICMJE) criteria for authorship for this article, take responsibility for the integrity of the work as a whole, and have given their approval for this version to be published.

Authors' Contributions. Substantial contributions to study conception and design: Juan José García Sánchez, Anna Bobrowska, Glen James, Eric Wittbrodt, Stephen Nolan; substantial contributions to analysis and interpretation of the data: Molly Murton, Danielle Goff-Leggett, Anna Bobrowska, Juan José García Sánchez, Glen James, Eric Wittbrodt, Stephen Nolan, Elisabeth Sörstadius, Roberto Pecoits-Filho, Katherine Tuttle; drafting the article or revising it critically for important intellectual content: Molly Murton, Danielle Goff-Leggett, Anna Bobrowska, Juan José García Sánchez, Glen James, Eric Wittbrodt, Stephen Nolan, Elisabeth Sörstadius, Roberto Pecoits-Filho, Katherine Tuttle; final approval of the version of the article to be published: Molly Murton, Danielle Goff-Leggett, Anna Bobrowska, Juan José García Sánchez, Glen James, Eric Wittbrodt, Stephen Nolan, Elisabeth Sörstadius, Roberto Pecoits-Filho, Katherine Tuttle. Roberto Pecoits-Filho and Katherine Tuttle are joint senior authors.

Disclosures. Molly Murton, Danielle GoffLeggett, Anna Bobrowska: Employees of Costello Medical Consulting Ltd. Juan José García Sánchez, Glen James, Eric Wittbrodt, Stephen Nolan, Elisabeth Sörstadius: AstraZeneca employees. Roberto Pecoits-Filho: Research grants from Fresenius Medical Care, speaker/ advisory board participation honoraria from AstraZeneca, AKEBIA, and Novo Nordisk. Katherine Tuttle: Consultant on CKD and diabetes for Eli Lilly and Company, Boehringer Ingelheim, AstraZeneca, Gilead, Goldfinch Bio, Novo Nordisk and Bayer.

Compliance with Ethics Guidelines. This article is based on previously conducted studies and does not contain any new studies with human participants or animals performed by any of the authors.

Open Access. This article is licensed under a Creative Commons Attribution-NonCommercial 4.0 International License, which permits any non-commercial use, sharing, adaptation, distribution and reproduction in any medium or format, as long as you give appropriate credit to the original author(s) and the source, provide a link to the Creative Commons licence, and indicate if changes were made. The images or other third party material in this article are included in the article's Creative Commons licence, unless indicated otherwise in a credit line to the material. If material is not included in the article's Creative Commons licence and your intended use is not permitted by statutory regulation or exceeds the permitted use, you will need to obtain permission directly from the copyright holder. To view a copy of this licence, visit http://creative commons.org/licenses/by-nc/4.0/.

\section{REFERENCES}

1. American Society of Nephrology (ASN), European Renal Association - European Dialysis and Transplant Association (ERA-EDTA), International Society of Nephrology (ISN). The hidden epidemic: worldwide, over 850 million people suffer from kidney diseases. 2018. https://www.asn-online.org/ news/2018/0626-Joint_Hidden_Epidem.pdf. Accessed Sept 2020.

2. Bello AK, Levin A, Tonelli M, et al. Global Kidney Health Atlas: a report by the International Society of Nephrology on the current state of organization and structures for kidney care across the globe. 2017. https://www.kidneycareuk.org/documents/ 52/ISN_Global_kidney_health_atlas.pdf. Accessed Sept 2020. 
3. Jha V, Garcia-Garcia G, Iseki K, et al. Chronic kidney disease: global dimension and perspectives. Lancet. 2013;382:260-72.

4. Bikbov B, Purcell CA, Levey AS, et al. Global, regional, and national burden of chronic kidney disease, 1990-2017: a systematic analysis for the Global Burden of Disease Study 2017. Lancet. 2020;395:709-33.

5. Kidney Care UK. An estimated 1 in 10 people worldwide have chronic kidney disease. 2017. https://www.kidneycareuk.org/news-and-campaigns/ news/estimated-1-10-people-worldwide-have-chronickidney-disease/. Accessed Dec 2019.

6. Xie Y, Bowe B, Mokdad AH, et al. Analysis of the global burden of disease study highlights the global, regional, and national trends of chronic kidney disease epidemiology from 1990 to 2016. Kidney Int. 2018;94:567-81.

7. GBD 2015 Mortality and Causes of Death Collaborators. Global, regional, and national life expectancy, all-cause mortality, and cause-specific mortality for 249 causes of death, 1980-2015: a systematic analysis for the Global Burden of Disease Study 2015. Lancet. 2016;388:1459-544.

8. GBD 2015 Disease and Injury Incidence and Prevalence Collaborators. Global, regional, and national incidence, prevalence, and years lived with disability for 310 diseases and injuries, 1990-2015: a systematic analysis for the Global Burden of Disease Study 2015. Lancet. 2016;388:1545-602.

9. Levin A, Stevens PE. Summary of KDIGO 2012 CKD guideline: behind the scenes, need for guidance, and a framework for moving forward. Kidney Int. 2014;85:49-61.

10. Iwagami M, Caplin B, Smeeth L, et al. Chronic kidney disease and cause-specific hospitalisation: a matched cohort study using primary and secondary care patient data. Br J Gen Pract. 2018;68:e512-23.

11. Golestaneh L, Alvarez PJ, Reaven NL, et al. All-cause costs increase exponentially with increased chronic kidney disease stage. Am J Manag Care. 2017;23: S163-s172.

12. Levey AS, Becker C, Inker LA. Glomerular filtration rate and albuminuria for detection and staging of acute and chronic kidney disease in adults: a systematic review. JAMA. 2015;313:837-46.

13. Hallan SI, Ritz E, Lydersen S, et al. Combining GFR and albuminuria to classify CKD improves prediction of ESRD. J Am Soc Nephrol. 2009;20:1069-77.
14. Gansevoort RT, de Jong PE. The case for using albuminuria in staging chronic kidney disease. J Am Soc Nephrol. 2009;20:465-8.

15. Levey AS, Tangri N, Stevens LA. Classification of chronic kidney disease: a step forward. Ann Intern Med. 2011;154:65-7.

16. Tonelli M, Muntner P, Lloyd A, et al. Using proteinuria and estimated glomerular filtration rate to classify risk in patients with chronic kidney disease: a cohort study. Ann Intern Med. 2011;154:12-21.

17. Coresh J. Update on the burden of CKD. J Am Soc Nephrol. 2017;28:1020-2.

18. Hill NR, Fatoba ST, Oke JL, et al. Global prevalence of chronic kidney disease-a systematic review and meta-analysis. PLoS One. 2016;11:e0158765.

19. Mills KT, Xu Y, Zhang W, et al. A systematic analysis of worldwide population-based data on the global burden of chronic kidney disease in 2010. Kidney Int. 2015;88:950-7.

20. Centre for Reviews and Dissemination. Systematic Reviews: CRD's guidance for undertaking reviews in health care: Centre for Reviews and Dissemination. 2009. https://www.york.ac.uk/media/crd/ Systematic_Reviews.pdf. Accessed Nov 2020.

21. Higgins JPT, Thomas J, Chandler J, et al. Cochrane Handbook for Systematic Reviews of Interventions: Cochrane. 2019. https://training.cochrane.org/ handbook/current. Accessed Nov 2020.

22. Munn Z, Moola S, Lisy K, et al. Methodological guidance for systematic reviews of observational epidemiological studies reporting prevalence and cumulative incidence data. Int $\mathrm{J}$ Evid Based Healthc. 2015;13:147-53.

23. Stengel B, Metzger M, Combe C, et al. Risk profile, quality of life and care of patients with moderate and advanced CKD: the French CKD-REIN Cohort Study. Nephrol Dial Transplant. 2019;34:277-86.

24. Hui X, Matsushita K, Sang Y, et al. CKD and cardiovascular disease in the Atherosclerosis Risk in Communities (ARIC) study: interactions with age, sex, and race. Am J Kidney Dis. 2013;62:691-702.

25. Levin A, Stevens PE, Bilous RW, et al. Kidney Disease: Improving Global Outcomes (KDIGO) CKD work group. KDIGO 2012 clinical practice guideline for the evaluation and management of chronic kidney disease. Kidney Int Suppl. 2013;3:1-150.

26. Odden MC, Amadu AR, Smit E, et al. Uric acid levels, kidney function, and cardiovascular mortality in US adults: National Health and Nutrition 
Examination Survey (NHANES) 1988-1994 and 1999-2002. Am J Kidney Dis. 2014;64:550-7.

27. United States Renal Data System. USRDS annual data report: Epidemiology of kidney disease in the United States. Chapter 1: CKD in the General Population. National Institutes of Health, National Institute of Diabetes and Digestive and Kidney Diseases, Bethesda, MD. 2018. https://www.usrds. org/annual-data-report/previous-adrs/. Accessed Dec 2019.

28. Tanner RM, Calhoun DA, Bell EK, et al. Prevalence of apparent treatment-resistant hypertension among individuals with CKD. Clin J Am Soc Nephrol. 2013;8:1583-90.

29. Lin B, Shao L, Luo Q et al. Prevalence of chronic kidney disease and its association with metabolic diseases: a cross-sectional survey in Zhejiang province, Eastern China. BMC Nephrol. 2014;15:36.

30. Wang F, He K, Wang J, et al. Prevalence and risk factors for CKD: a comparison between the adult populations in China and the United States. Kidney Int Rep. 2018;3:1135-43.

31. Pani A, Bragg-Gresham J, Masala M, et al. Prevalence of CKD and its relationship to eGFR-related genetic loci and clinical risk factors in the SardiNIA study cohort. J Am Soc Nephrol. 2014;25:1533-44.

32. Ruiz-Hurtado G, Ruilope LM, de la Sierra A, et al. Association between high and very high albuminuria and nighttime blood pressure: influence of diabetes and chronic kidney disease. Diabetes Care. 2016;39:1729-37.

33. Villain C, Metzger M, Combe C, et al. Prevalence of atheromatous and non-atheromatous cardiovascular disease by age in chronic kidney disease. Nephrol Dial Transplant. 2018;35:827-36.

34. Levey AS, Eckardt K-U, Dorman NM, et al. Nomenclature for kidney function and disease: report of a kidney disease: improving global outcomes (KDIGO) consensus conference. Kidney Int. 2020;97:1117-29.

35. Iimori S, Naito S, Noda Y, et al. Prognosis of chronic kidney disease with normal-range proteinuria: the CKD-ROUTE study. PLoS One. 2018;13:e0190493.

36. Tuttle KR, Alicic RZ, Duru OK, et al. clinical characteristics of and risk factors for chronic kidney disease among adults and children: an analysis of the CURE-CKD registry. JAMA Netw Open. 2019;2: e1918169.

37. Matsushita $\mathrm{K}$, van der Velde $\mathrm{M}$, Astor BC, et al. Association of estimated glomerular filtration rate and albuminuria with all-cause and cardiovascular mortality in general population cohorts: a collaborative meta-analysis. Lancet. 2010;375:2073-81.

38. Polkinghorne KR. Estimated glomerular filtration rate versus albuminuria in the assessment of kidney function: what's more important? Clin Biochem Rev. 2014;35:67-73.

39. Ene-Iordache B, Perico N, Bikbov B, et al. Chronic kidney disease and cardiovascular risk in six regions of the world (ISN-KDDC): a cross-sectional study. Lancet Glob Health. 2016;4:e307-19.

40. GBD 2013 Mortality and Causes of Death Collaborators. Global, regional, and national age-sex specific all-cause and cause-specific mortality for 240 causes of death, 1990-2013: a systematic analysis for the Global Burden of Disease Study 2013. Lancet. 2015;385:117-71.

41. Orlandi PF, Huang J, Fukagawa M, et al. A collaborative, individual-level analysis compared longitudinal outcomes across the International Network of Chronic Kidney Disease (iNETCKD) cohorts. Kidney Int. 2019;96:1217-33.

42. Pecoits-Filho R, Fliser D, Tu C, et al. Prescription of renin-angiotensin-aldosterone system inhibitors (RAASi) and its determinants in patients with advanced CKD under nephrologist care. J Clin Hypertens (Greenwich). 2019;21:991-1001.

43. Stevens PE, Levin A, Kidney Disease: Improving Global Outcomes Chronic Kidney Disease Guideline Development Work Group Members. Evaluation and management of chronic kidney disease: synopsis of the Kidney Disease: Improving Global Outcomes 2012 clinical practice guideline. Ann Intern Med. 2013;158:825-30.

44. Kazancioğlu R. Risk factors for chronic kidney disease: an update. Kidney Int Suppl. 2013;3:368-71.

45. Whitman W. US Renal Data System, USRDS 2004 Annual Data Report: Atlas of End-Stage Renal Disease in the United States: Bethesda, National Institutes of Health, National Institute of Diabetes and Digestive and Kidney Diseases. 2004. https:// www.usrds.org/annual-data-report/previous-adrs/. Accessed Dec 2019.

46. Dolgin M, Fox AC, Gorlin R, et al. Nomenclature and criteria for diagnosis of diseases of the heart and great vessels. Boston: Lippincott Williams and Wilkins; 1994.

47. Ballew SH, Chen Y, Daya NR, et al. Frailty, kidney function, and polypharmacy: the Atherosclerosis Risk in Communities (ARIC) study. Am J Kidney Dis. 2017;69:228-36. 
48. Ishigami J, Grams ME, Chang AR, et al. CKD and risk for hospitalization with infection: the Atherosclerosis Risk in Communities (ARIC) study. Am J Kidney Dis. 2017;69:752-61.
49. Waheed S, Matsushita K, Sang Y, et al. Combined association of albuminuria and cystatin C-based estimated GFR with mortality, coronary heart disease, and heart failure outcomes: the Atherosclerosis Risk in Communities (ARIC) Study. Am J Kidney Dis. 2012;60:207-16. 